\title{
Generation of mature human myelomonocytic cells through expansion and differentiation of pluripotent stem cell-derived lin-CD34+CD43+CD45+ progenitors
}

\author{
Kyung-Dal Choi, ${ }^{1}$ Maxim A. Vodyanik, ${ }^{2}$ and Igor I. Slukvin',2
}

${ }^{1}$ Department of Pathology and Laboratory Medicine and 2National Primate Research Center, University of Wisconsin, Madison, Wisconsin, USA.

\begin{abstract}
Basic research into human mature myelomonocytic cell function, myeloid lineage diversification and leukemic transformation, and assessment of myelotoxicity in preclinical drug development requires a constant supply of donor blood or bone marrow samples and laborious purification of mature myeloid cells or progenitors, which are present in very small quantities. To overcome these limitations, we have developed a protocol for efficient generation of neutrophils, eosinophils, macrophages, osteoclasts, DCs, and Langerhans cells from human embryonic stem cells (hESCs). As a first step, we generated lin- $\mathrm{CD} 34^{+} \mathrm{CD} 43^{+} \mathrm{CD} 45^{+}$hematopoietic cells highly enriched in myeloid progenitors through coculture of hESCs with OP9 feeder cells. After expansion in the presence of GM-CSF, these cells were directly differentiated with specific cytokine combinations toward mature cells of particular types. Morphologic, phenotypic, molecular, and functional analyses revealed that hESC-derived myelomonocytic cells were comparable to their corresponding somatic counterparts. In addition, we demonstrated that a similar protocol could be used to generate myelomonocytic cells from induced pluripotent stem cells (iPSCs). This technology offers an opportunity to generate large numbers of patient-specific myelomonocytic cells for in vitro studies of human disease mechanisms as well as for drug screening.
\end{abstract}

\section{Introduction}

Myeloid cells originate from multipotent hematopoietic stem cells in the bone marrow and consist of granulocytes (neutrophils, eosinophils, basophils) and cells of monocyte/ macrophage lineage including DCs and osteoclasts. These cells play a critical role in innate and adaptive immunity, inflammatory reactions, and bone remodeling. Transformed myeloid cells give rise to neoplasia, such as acute and chronic myeloid leukemia. Substantial gains in the understanding of myeloid cell development and leukemogenesis have been made over the past several decades through identification, isolation, and targeted manipulation of hematopoietic stem cells and progenitors $(1,2)$. The majority of these studies are based on mouse models because of the ease with which mouse cells can be manipulated and assayed for hematopoietic lineage commitment potential. In vitro differentiation studies using human bone marrow cells are hampered by the limited availability of bone marrow myeloid precursors and the complexity of genetic manipulation of bone marrow cells. While myeloid leukemia cell lines are frequently used to study differentiation of myeloid cells, these cells have a highly abnormal karyotype and often display functional differences from their normal myeloid counterparts (3-6).

Human embryonic stem cells (hESCs) are pluripotent stem cells capable of indefinite self-renewal and differentiation toward all 3 germ layers (ectoderm, endoderm, and mesoderm) (7). In vitro differentiation of hESCs provides a unique opportunity to study early hematopoietic commitment and specification of different hematopoietic lineages. In addition, establishing conditions for

Conflict of interest: Igor I. Slukvin is scientific founder and stockholder of Cellular Dynamics International.

Citation for this article: J. Clin. Invest. 119:2818-2829 (2009). doi:10.1172/JCI38591. directed differentiation of hESCs toward a particular hematopoietic lineage will allow the functional analysis of genes essential for lineage expansion and maturation without limitation in terms of cell numbers and heterogeneity of progenitors. Recently, pluripotent stem cell lines have been obtained from human fibroblasts through insertion of certain genes critical for the maintenance of pluripotency of hESCs (8-10). These so-called human induced pluripotent stem cells (hiPSCs) behave similarly to hESCs, i.e., they are capable of self-renewal and large-scale expansion and differentiation toward all 3 germ layers. hiPSC lines generated from patients with various diseases could be used to obtain any type of progenitor or differentiated cell carrying a particular genetic trait at the cellular level, thus providing a unique opportunity to analyze disease pathogenesis in vitro. We established a system for efficient hematopoietic differentiation of hESCs into hematopoietic cells through coculture with OP9 bone marrow stromal cells (11) and characterized the two subpopulations of the most primitive multipotent hematopoietic cells to appear in OP9 cocultures of hESCs on the basis of their common expression of CD43 and differential expression of CD 45 . The lin ${ }^{-} \mathrm{CD} 34^{+} \mathrm{CD} 43^{+} \mathrm{CD} 45^{-}$cells with broad lymphomyeloid differentiation potential appear first in coculture. Later, lin $^{-} \mathrm{CD} 34^{+} \mathrm{CD} 43^{+} \mathrm{CD} 45^{+}$cells enriched in myeloid progenitors emerge (12). Recently we demonstrated that a similar pattern of hematopoietic differentiation is observed when hiPSCs differentiate into blood cells in coculture with OP9 (13). Here we report a method for efficient generation of mature myelomonocytic cells from hESCs and hiPSCs through expansion of inn $^{-} \mathrm{CD} 34^{+} \mathrm{CD} 43^{+} \mathrm{CD} 45^{+}$myeloid-skewed multipotent hematopoietic cells with GM-CSF, followed by their directed differentiation toward neutrophils, eosinophils, macrophages, DCs, Langerhans cells (LCs), and osteoclasts using specific combinations of 

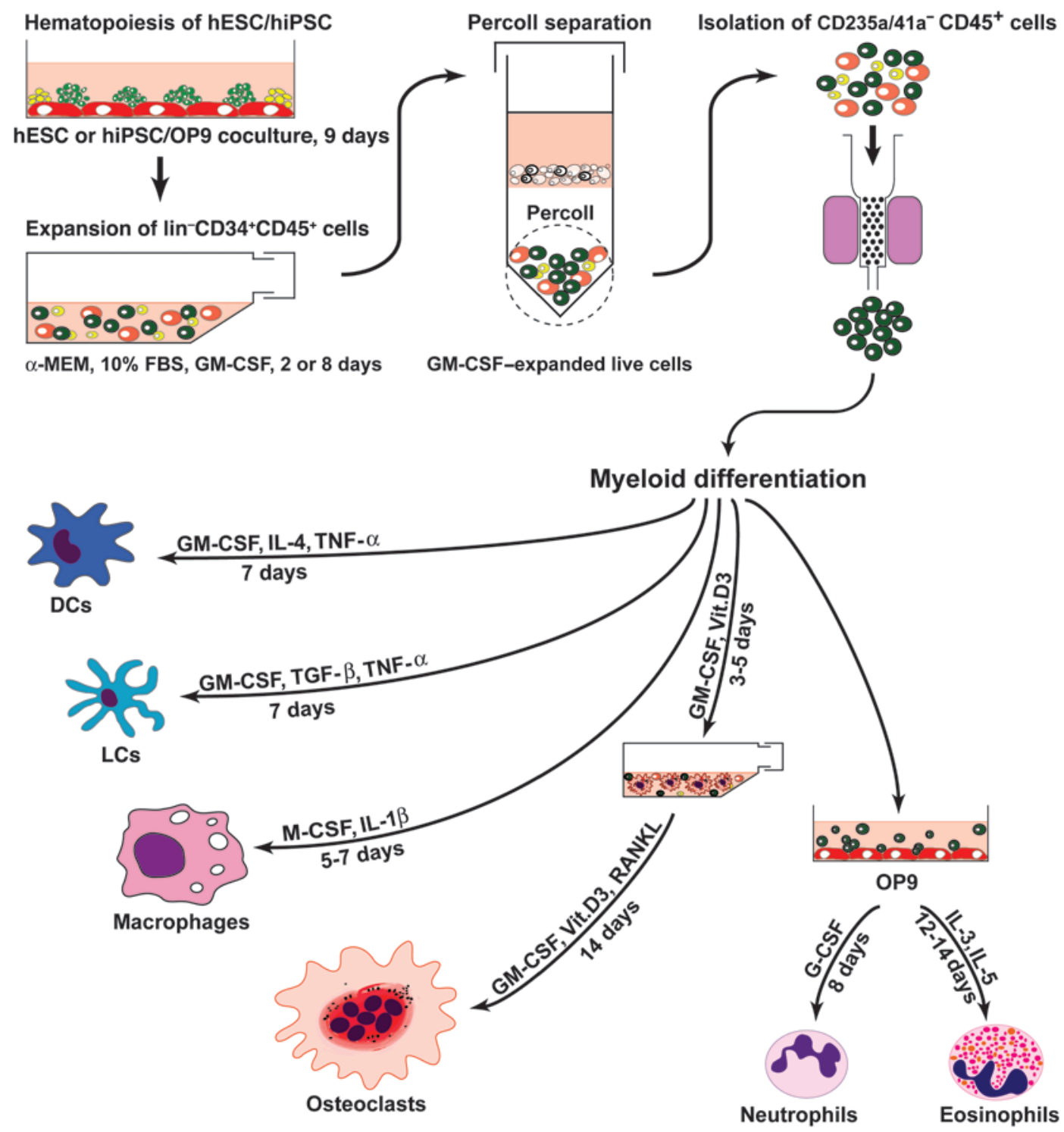

Figure 1

Schematic diagram of the differentiation protocol used for myeloid cell generation from hESCs and hiPSCs. Vit.D3, vitamin D3.

cytokines and growth factors. This method makes it feasible to produce myelomonocytic cells on a large scale. Depending on cell type, $10^{7}$ to $4 \times 10^{9}$ mature cells could be obtained from one 6 -well plate of hESCs or hiPSCs.

\section{Results}

Short treatment with GM-CSF expands bESC-derived CD235a/CD41a $\mathrm{CD} 34^{+} \mathrm{CD} 45^{+}$cells enriched in myeloid CFCs. A schematic diagram of the differentiation protocol is presented in Figure 1. As shown in Figure 2A, 3 major subsets of hematopoietic cells could be identified on day 9 of hESC/OP9 coculture: $\mathrm{CD} 43^{+} \mathrm{CD} 235 \mathrm{a}^{+} \mathrm{CD} 41 \mathrm{a}^{+/-}$ (erythro-megakaryocytic), $\operatorname{lin}^{-} \mathrm{CD} 34^{+} \mathrm{CD} 43^{+} \mathrm{CD} 45^{-}$(multipotent with broad lymphomyeloid potential), and $\mathrm{lin}^{-} \mathrm{CD} 34^{+} \mathrm{CD} 43^{+} \mathrm{CD} 45^{+}$ (myeloid-skewed) cells (12). After dissociation and reaggregation of day $9 \mathrm{hESC} / \mathrm{OP} 9$ coculture cells in nonadherent conditions, CD $45^{+}$ cells were expanded by addition of $200 \mathrm{ng} / \mathrm{ml} \mathrm{GM-CSF}$. In these cultures, hematopoietic cells were released from aggregates into suspension and could be easily isolated by Percoll-based density gradient centrifugation without an additional enzymatic digestion step starting from day 2 of expansion (Figure 1). Analysis of kinetics demonstrated that the proportion of CD235a/CD $41 \mathrm{a}^{+}$erythromegakaryocytic cells decreased following treatment with GM-CSF, while the number of CD235a/CD41a ${ }^{-} \mathrm{CD} 45^{+}$cells increased after 8 days of cultures (Figure 2, A, B, C, and E). However, the maximum expansion of bipotential granulocyte-macrophage CFCs (GM-CFCs) and unipotential macrophage CFCs (M-CFCs) within the $\mathrm{CD} 235 \mathrm{a} / \mathrm{CD} 41 \mathrm{a}^{-} \mathrm{CD} 45^{+}$population was observed on day 2 of culture with GM-CSF (Figure 2D). At this time, the most primitive myeloid cells, granulocyte/erythrocyte/macrophage/megakaryocyte CFCs (GEMM-CFCs) were also detected in substantial numbers. The total numbers of GEMM-CFCs, GM-CFCs, and M-CFCs gradually decreased after 2-3 days of expansion with GM-CSF. 
A

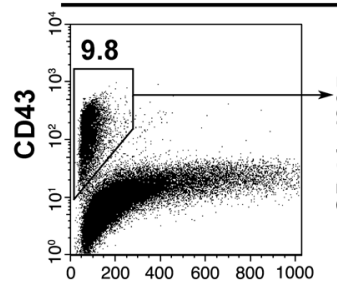

SSC

hESC/OP9 coculture $d 9$

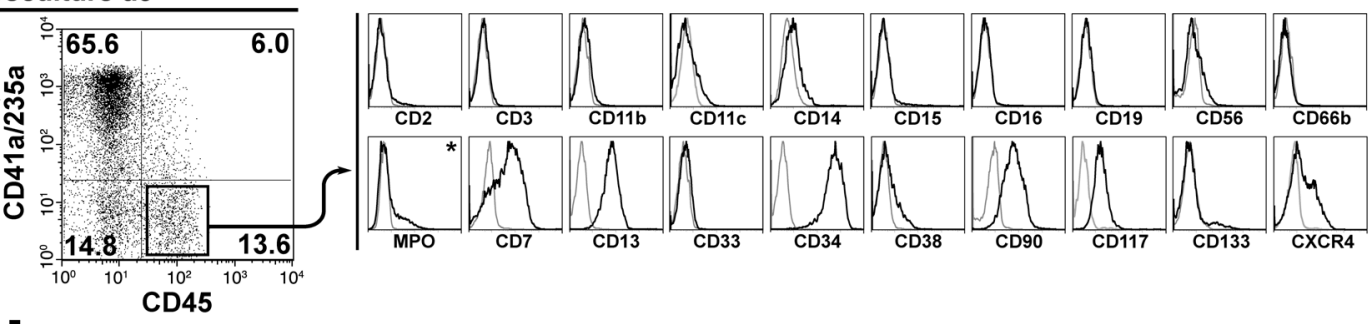

B After 2-day expansion with GM-CSF
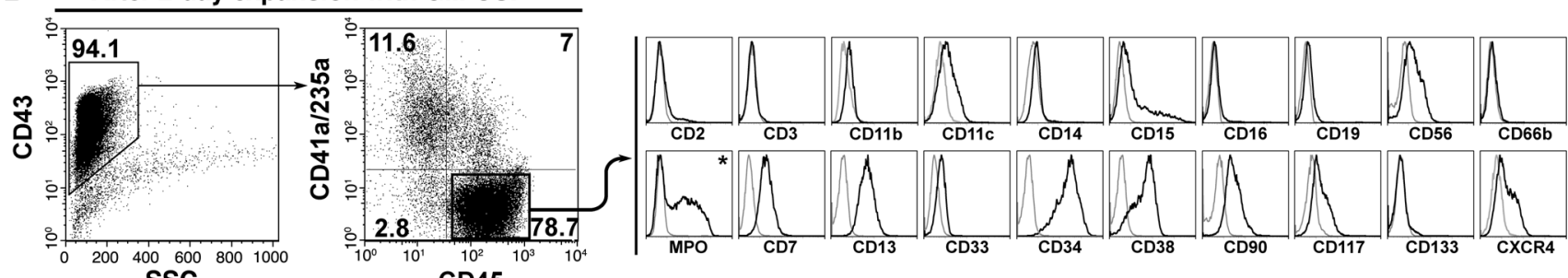

SSC

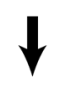

C After 8-day expansion with GM-CSF

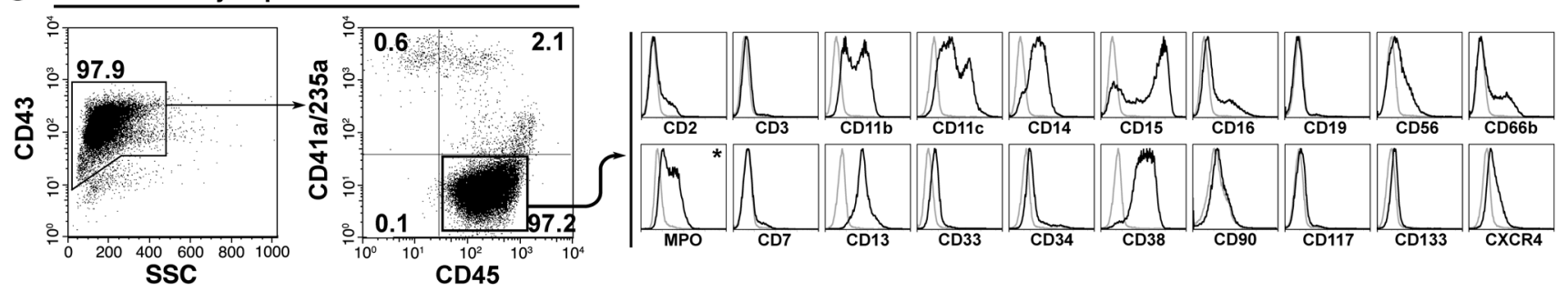

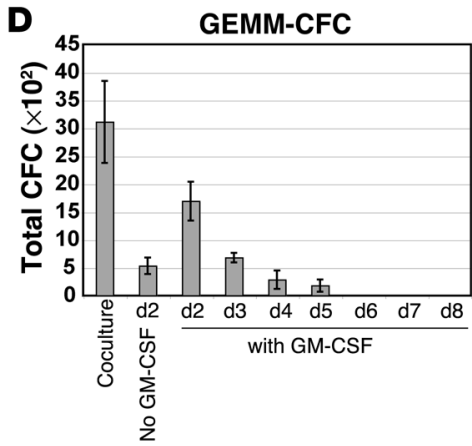

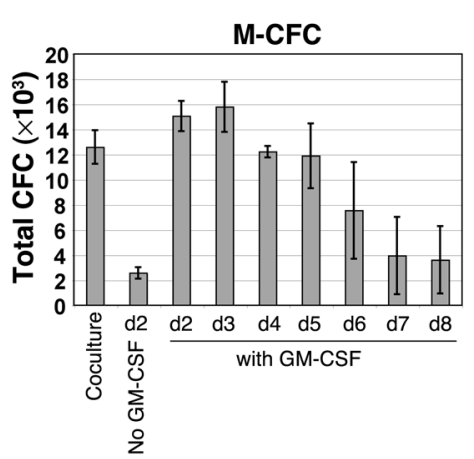

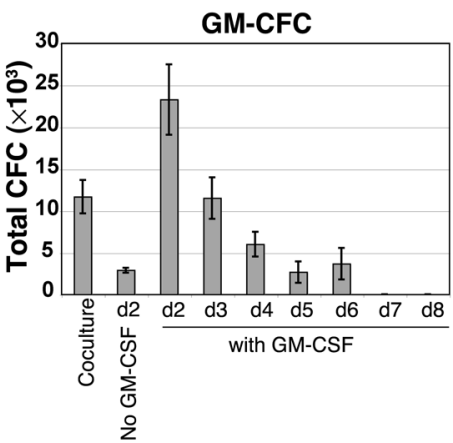

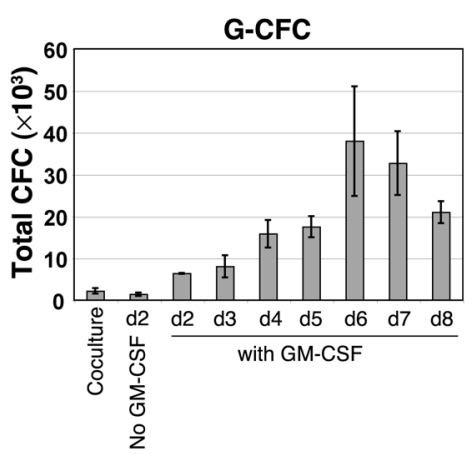

E

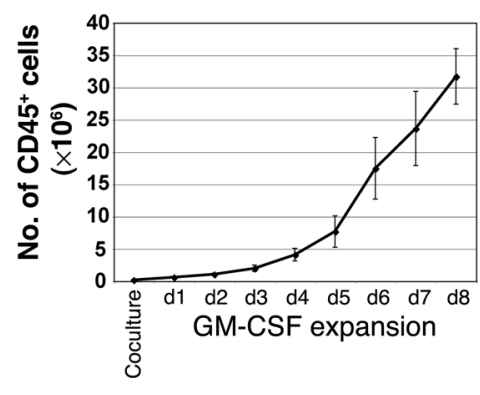

$F_{\text {G-CFC from d2 CD45+ cells G-CFC from d6 CD45+ cells }}$
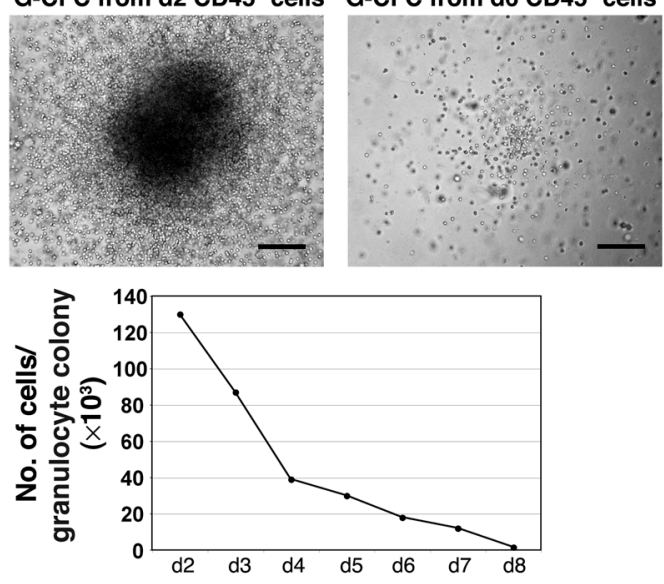


\section{Figure 2}

Characterization of $\mathrm{H} 1 \mathrm{hESC}-$ derived myeloid progenitors generated in OP9 coculture and expanded with GM-CSF. Phenotype of CD235a/ CD41a-CD45+ cells generated on day 9 (d9) of hESC/OP9 coculture (A) and after 2 (B) and 8 days (C) expansion with GM-CSF; the asterisk indicates intracellular staining. A representative of 3-5 independent experiments is shown. SSC, side scatter. Values within dot plots indicate the percentage of cells in the respective quadrants. (D) Absolute number of myeloid CFCs generated from one $10-\mathrm{cm}$ dish of hESC/ OP9 coculture and from CD235a/CD41a-CD45+ cells obtained from the same dish and expanded in the presence of GM-CSF for 2-8 days. Results are mean \pm SEM of 3-5 independent experiments. (E) Kinetics of CD235a/CD41a ${ }^{-}$CD $45^{+}$cell expansion with GM-CSF. Data are expressed as the number of CD235a/CD $41 a^{-} C D 45^{+}$cells generated from one 10-cm dish of hESC/OP9 coculture and following expansion with GM-CSF. Results are mean \pm SEM of 3-5 experiments. (F) Typical morphology of granulocytic colony obtained from CD235a/CD41aCD45+ cells expanded with GM-CSF for 2 and 6 days (scale bars: 100 $\mu \mathrm{m})$. The graph shows cell numbers per single granulocytic colony obtained from cells expanded with GM-CSF for 2-8 days.

In contrast, the total number of unipotential G-CFCs gradually increased up to 6 days of culture with GM-CSF. However, we noted significant differences in the size of granulocyte colonies at different time points. As shown in Figure 2F, granulocyte colonies obtained after 2 days of expansion with GM-CSF were much larger and contained up to $70-150$ times more cells per single colony as compared with those colonies obtained after 6-8 days of expansion, indicative of a gradual decrease in the proliferative potential of G-CFCs. CD235a/CD41a-CD45 ${ }^{+}$cells obtained after 2 days expansion with GM-CSF retained CD34 expression and lacked the majority of lineage-specific markers, although upregulation of CD38, myeloperoxidase (MPO), CD15, and CD56 expression and downregulation of CD90 and CD117 expression were apparent (Figure 2B). On cytospins, these cells displayed typical myeloblast morphology, with cells undergoing mitosis readily apparent (Figure $3 \mathrm{~A})$. At day 8 of GM-CSF expansion, $\mathrm{CD} 45^{+}$cells lost expression of primitive hematopoietic cell markers CD34, CD90, and CD117 and showed conspicuous upregulation of myeloid lineage markers CD11b, CD11c, CD14, CD15, CD16, CD66b, and MPO (Figure 2C). Most cells displayed promyelocyte and myelocyte morphology, with cells at more advanced stages of maturation and occasional myeloblasts also identified (data not shown). Essentially no contaminating OP9 cells were detected in GM-CSF-expanded cell samples (Supplemental Figure 1; supplemental material available online with this article; doi:10.1172/JCI38591DS1).

GM-CSF-expanded CD235a/CD41 $a^{-} C D 34^{+} C D 45^{+}$cells generate almost the entire spectrum of mature and fully functional myelomonocytic cells. Because CD235a/CD41a-CD $34^{+} \mathrm{CD} 45^{+}$cells after 2 days expansion with GM-CSF showed the highest number of CFCs, we used these cells to develop conditions for obtaining mature myelomonocytic cells from hESCs. To induce differentiation toward neutrophils, we cultured CD235a/CD $41 \mathrm{a}^{-} \mathrm{CD} 34^{+} \mathrm{CD} 45^{+}$cells in serum-containing medium on OP9 cells in the presence of G-CSF. An almost pure population of cells with typical neutrophil morphology (Figure 3D) and phenotype (Figure 4A) was generated in this condition after 7-9 days of culture. It should be noted that hESC-derived neutrophils showed a high level of CD14 expression (Figure 4A). In general, CD14 is considered a marker of monocytes in peripheral blood, although it is well known that CD14 is also expressed on granulocytes, but at a much lower level $(14,15)$. Our data indicate that both granulocytic and monocytic cells generated in vitro express a high level of CD14 and analysis of CD14 expression should not be used for discrimination of monocytic lineage from granulocytic in in vitro differentiation cultures. The cause of the high CD14 expression in in vitro generated neutrophils is not clear, but it could be related to the upregulating effect of CSFs on CD14 expression (15). The hESC-derived neutrophils expressed neutrophil-specific genes AZU1 (azurocidin 1), ELANE (elastase 2), CTSG (cathepsin G), and PRTN3 (proteinase 3; Figure 4C). The level of PRTN3 expression in hESC-derived neutrophils was much higher as compared with that in peripheral blood and $\mathrm{CD}^{+} 4^{+}$cell-derived neutrophils, while $A Z U$ expression was notably lower (Supplemental Figure 2). The majority of the cells also expressed lactoferrin (the constituent of neutrophil granules) as detected by flow cytometry (Figure 4A). In response to PMA, hESC-derived neutrophils characteristically produced superoxide at a level comparable to somatic $\mathrm{CD} 34^{+}$cell-derived neutrophils, but lower as compared with freshly isolated peripheral blood neutrophils (Figure 4F). In addition, hESC-derived neutrophils were capable of ingesting zymosan and E. coli particles (Figure 4E) and showed a chemotactic response to $N$-formyl-Met-Leu-Phe (fMLP) (Figure 4H). However, we noted decreased chemotactic response of hESC-derived neutrophils in comparison with somatic neutrophils due to an increase in spontaneous migration.

When CD235a/CD $41 \mathrm{a}^{-} \mathrm{CD} 34^{+} \mathrm{CD} 45^{+}$cells were cultured on OP9 in serum-containing medium with IL-3 and IL-5, an essentially pure population of eosinophils was generated. Characteristically, hESC-derived eosinophils had abundant cytoplasm filled by numerous coarse, orange-red granules of uniform size and a classic 2-lobed nucleus (Figure 3E). The hESC-derived eosinophils, similar to peripheral blood eosinophils (16), lacked CD16, CD64, CD66b, CD123 (IL-3R), and FceRII (CD23) expression (Figure 4B). Intracellular and cytochemical staining revealed expression of 2 of the eosinophil granule proteins, major basic protein (MBP; crystalloid core component) and eosinophil peroxidase (EPO; one of the matrix components of granules) in hESC-derived eosinophils (Figure 4B and Figure 3F). mRNA encoding the Charcot-Leyden crystal (CLC) protein (lysophospholipase or galectin 10) was also detected (Figure 4D). No significant differences were observed in the level of CLC and EPO expression in hESC- and somatic CD34+ cell-derived eosinophils (Supplemental Figure 2). Reactive oxygen species were produced in hESC-derived eosinophils stimulated with PMA. Furthermore, $\mathrm{O}_{2}^{-}$production from hESC-eosinophils was similar to that from adult $\mathrm{CD} 34^{+}$cell-derived eosinophils (Figure 4G). However, hESC-derived eosinophils showed a decreased chemotactic response to $\mathrm{MPL}$ when compared with their somatic counterpart (Figure 4I). Whereas we employed the OP9 feeder in the granulocyte differentiation system, eosinophils and neutrophils could also be generated in feeder-free conditions, although with much lower efficiency (data not shown).

Macrophages were generated by culture of CD235a/CD 41a $\mathrm{CD} 34^{+} \mathrm{CD} 45^{+}$cells in serum-containing medium with $\mathrm{M}-\mathrm{CSF}$ and IL-1 $\beta$. Cells obtained in these conditions had typical macrophage morphology (Figure 3I) and expressed CD115 (M-CSFR), CD163, CD14, and CD68 (Figure 5C). DCs were obtained through culture of $\mathrm{CD} 235 \mathrm{a} / \mathrm{CD} 41 \mathrm{a}^{+} \mathrm{CD} 45^{+}$cells in serum-free medium with the addition of GM-CSF, IL- 4 , and TNF- $\alpha$, while GM-CSF, TNF- $\alpha$, and TGF- $\beta$ were used to generate LCs. After 9 days, $20.2 \% \pm 3.2 \%$ $\mathrm{CD}_{1} \mathrm{a}^{+}$cells were detected in DC cultures and $10.3 \% \pm 2.0 \% \mathrm{CD} \mathrm{a}^{+}$ cells in LC cultures. Isolated CD1 $\mathrm{a}^{+}$DCs and LCs showed dendritic 
A

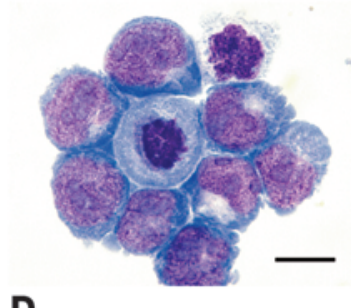

D

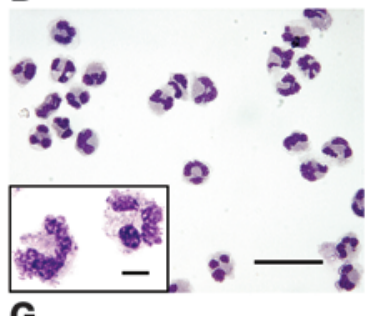

G

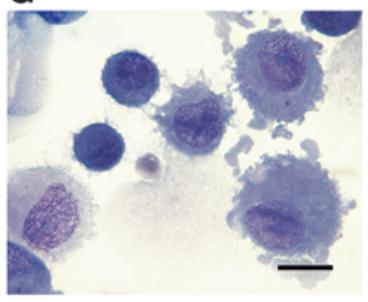

$\mathbf{J}$

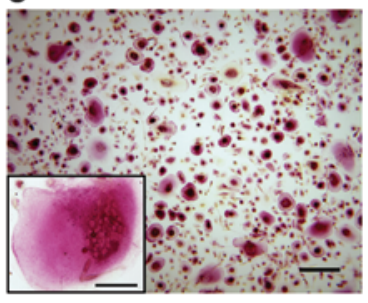

B

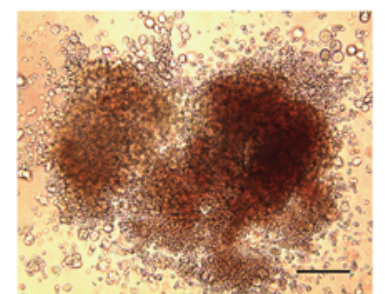

E

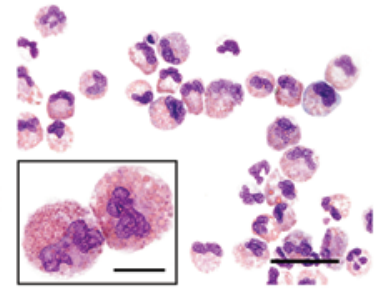

H

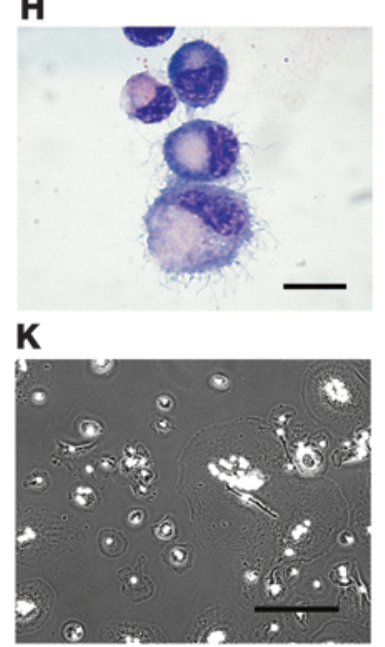

C

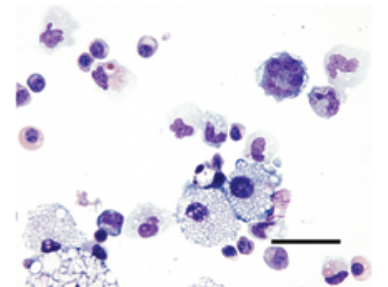

F

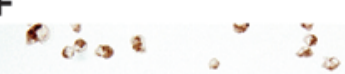

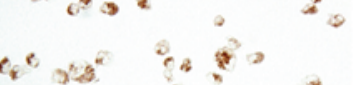

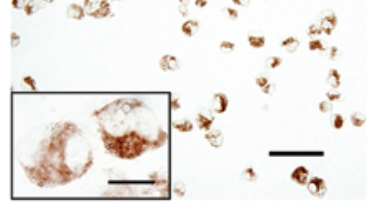

I

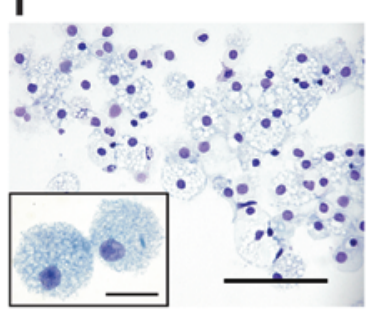

L

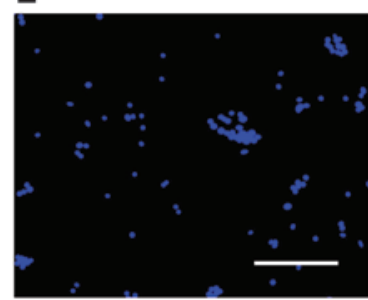

\section{Figure 3}

Morphology and cytochemical features of $\mathrm{H} 1$ hESC-derived myeloid progenitors and differentiated myelomonocytic cells. (A) Wright-stained cytospins of H1-derived CD235a/CD41a-CD45+ cells after 2 days expansion with GM-CSF (scale bar: $10 \mu \mathrm{m}$ ). (B) Typical GEMM-CFC generated from day 2 GM-CSF-expanded cells (scale bar: $200 \mu \mathrm{m}$ ). Wright-stained cytospins of GEMM-CFC (scale bar: $40 \mu \mathrm{m}$ ) (C), hESCderived mature neutrophils (scale bar: $25 \mu \mathrm{m}$; inset, $5 \mu \mathrm{m}$ ) (D), eosinophils (scale bar: $40 \mu \mathrm{m}$; inset, $10 \mu \mathrm{m})(E), C D 1 a^{+}$cells isolated from DC (scale bar: $10 \mu \mathrm{m})(\mathbf{G})$ and LC (scale bar: $10 \mu \mathrm{m}$ ) (H) cultures, and macrophages (scale bar: 100 $\mu \mathrm{m}$; inset, $20 \mu \mathrm{m})(\mathbf{I})$. (F) Cytochemical staining for eosinophil-specific (cyanide-resistant) peroxidase of hESC-derived eosinophils (scale bar: $50 \mu \mathrm{m}$; inset, $10 \mu \mathrm{m})$. (J) Cytochemical staining for TRAP of hESC-derived osteoclasts (scale bar: $300 \mu \mathrm{m}$; inset, $100 \mu \mathrm{m}$ ). Phase-contrast $(\mathbf{K})$ and corresponding DAPI staining (L) of osteoclasts to demonstrate multinucleation (scale bar: $200 \mu \mathrm{m}$ ). projections and veils typical of cells of dendritic lineage (Figure $3, \mathrm{G}$ and $\mathrm{H}$ ). In contrast to DCs, CD1 ${ }^{+}$cells in LC cultures expressed intracellular Langerin (CD207; a C-type lectin of LCs), E-cadherin, and cutaneous lymphocyte-associated antigen (CLA); had a CD14-DC-SIGN ${ }^{-} \mathrm{CD} 11 \mathrm{~b}^{\text {lo }}$ phenotype (Figure $5 \mathrm{~B}$ ); and were lacking in CCL17 and CCL13 chemokines, IRF4 transcription factor, and matrix metalloprotease MMP12 transcripts (Figure 5F), consistent with the LC nature of these cells $(17,18)$. Both DCs and LCs displayed a phenotype typical of antigen-presenting cells, including expression of costimulatory molecules (CD80, CD86, and CD40) and a high level of HLA-DR (Figure 5, A-C). However, DCs and LCs could be distinguished from macrophages by CD1a ${ }^{\text {hi }}$ CD $1 c^{+} H L A-D R{ }^{\text {hi }}$ CD14lo/-CD115-CD 163- phenotype (Figure $5, \mathrm{~A}-\mathrm{C}$ ). hESC-derived macrophages, DCs, and LCs were functional, as demonstrated by their ability to uptake and process a self-quenched conjugate of ovalbumin (DQ-OVA) (Figure 5D) and allostimulate naive and adult $\mathrm{T}$ cells in mixed lymphocyte reaction (Figure 5E). As expected, macrophages induced a much weaker alloresponse than did DCs and LCs.

The addition of vitamin D3 to hESC-derived CD235a/CD41a$\mathrm{CD} 34^{+} \mathrm{CD} 45^{+}$cells cultured in nonadherent conditions in the presence of GM-CSF was the most critical factor for inducing and expanding osteoclast precursors. When osteoclast precursors were transferred into conventional cell culture plates and cultured in the presence of vitamin D3 and RANKL for an additional 7-14 days, a pure population of mature tartrate-resistant acid phosphatasepositive (TRAP-positive) multinucleated osteoclasts was generated (Figure 3, J-L). As demonstrated by PCR and flow cytometry, hESC-derived osteoclasts expressed vitronectin (VTNR) and calcitonin receptors (CALCR), cathepsin $\mathrm{K}(C T S K)$, and RANK (Figure 6 , $A$ and $B$ ). While no significant differences were found in expression of RANK, CALCR, and VTNR by hESC- and CD $34^{+}$cell-derived osteoclasts, the level of CTSK expression was remarkably higher in osteoclasts generated from hESCs (Supplemental Figure 2). Osteoclasts generated from hESCs, in contrast to macrophages, were capable of resorbing mineralized matrix (Figure 6, C-F).

All types of myeloid cells were also generated from H9 hESCs, but the yield was less than that obtained from H1 hESCs, primarily due to less efficient generation of $\mathrm{lin}^{-} \mathrm{CD} 34^{+} \mathrm{CD} 43^{+} \mathrm{CD} 45^{+}$cells in H9/OP9 cocultures (Supplemental Table 1).

Optimization of differentiation protocol to increase output of mature myeloid cells and generation of mature myelomonocytic cells from biPSCs. The above-described studies demonstrated that $\operatorname{lin}^{-} \mathrm{CD} 34^{+} \mathrm{CD} 45^{+}$ myeloid progenitors with the potential to differentiate into almost the entire spectrum of myelomonocytic cells could be obtained from hESCs in sufficient quantities for differentiation, func- 


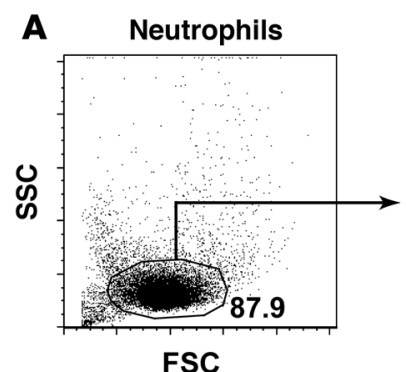

FSC

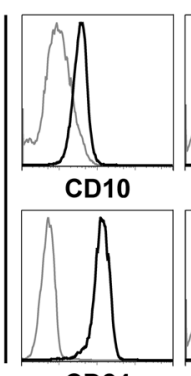

CD24

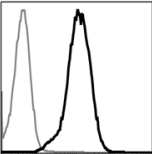

CD11b

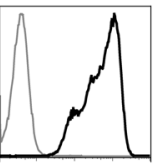

CD32

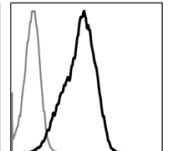

CD11c

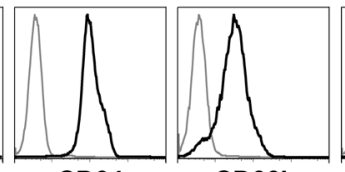

CD66b
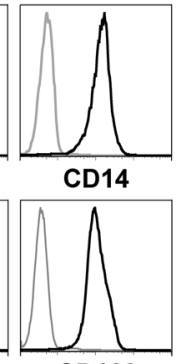

CD123

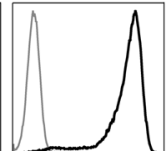

CD15

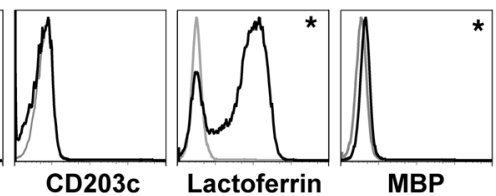

B

Eosinophils
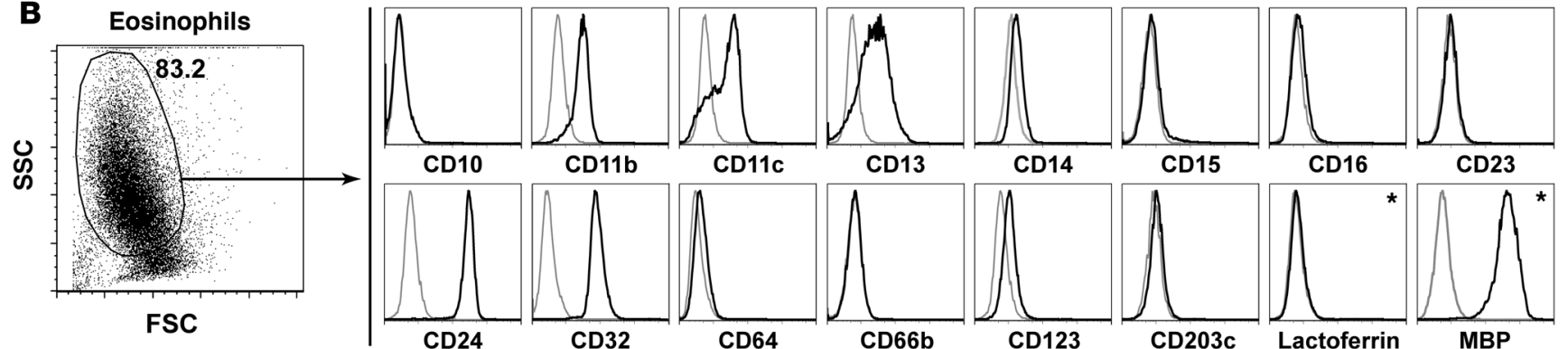

C

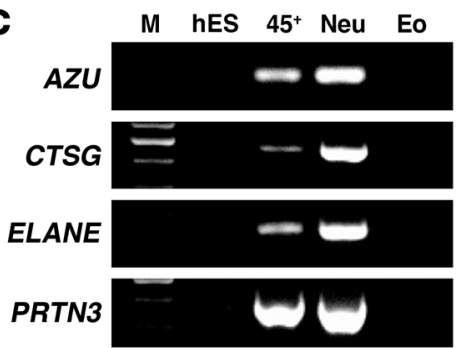

D

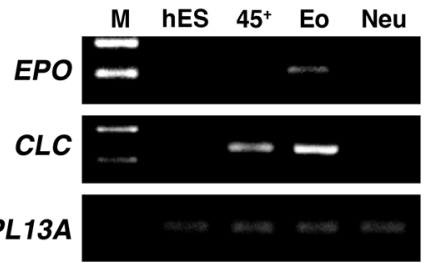

E

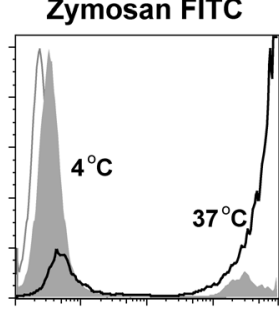

E. coli FITC

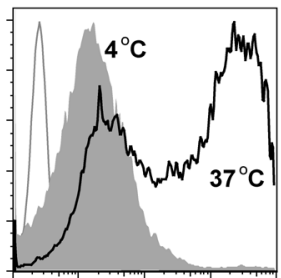

RPL13A
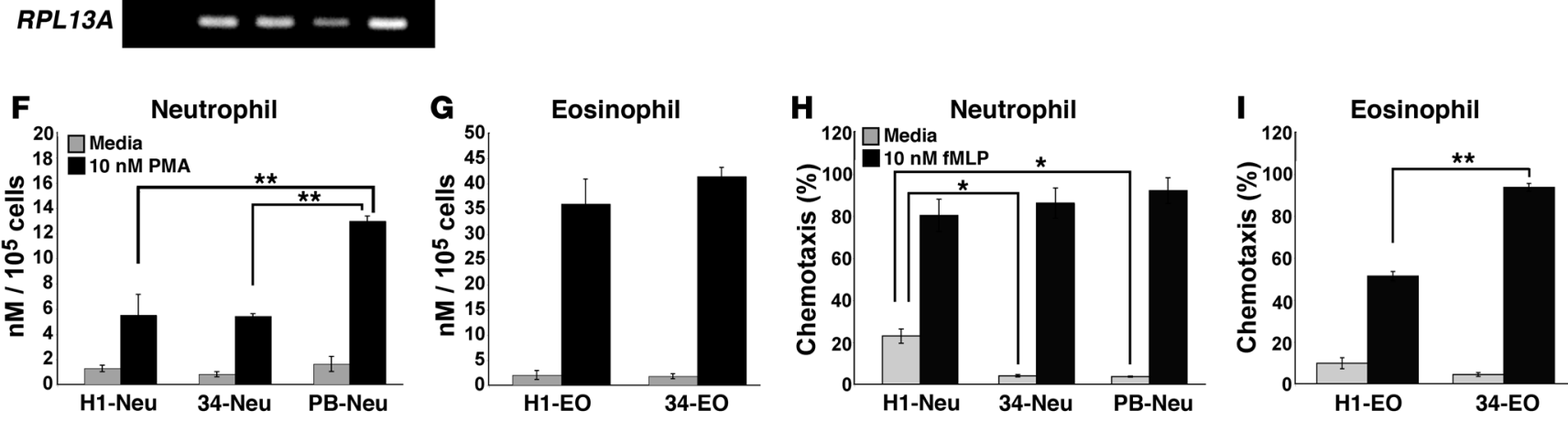

Figure 4

Phenotypic, molecular, and functional analysis of $\mathrm{H} 1 \mathrm{hESC}$-derived eosinophils and neutrophils obtained from isolated CD235a/CD41a-CD45+ cells after 2 days expansion with GM-CSF. FACS analysis of phenotype of hESC-derived neutrophils (A) and eosinophils (B). Plots show isotype control (gray) and specific antibody (black) histograms; asterisks indicate intracellular staining. Values within dot plots indicate the percentage of cells within the corresponding gate. A representative of 10 independent experiments is shown. Analysis of neutrophil and eosinophil-specific gene expression in hESC-derived neutrophils (C) and eosinophils (D) by RT-PCR. M, molecular weight markers; hES, undifferentiated hESCs; $45^{+}$, hESC-derived CD235a/CD41a-CD45+ cells isolated after 2 days expansion with GM-CSF; Neu, neutrophils; Eo is eosinophils. (E) Phagocytosis of zymozan and $E$. coli particles by hESC-derived neutrophils. Plots show histograms for isotype control (open gray) and cells incubated at $4^{\circ} \mathrm{C}$ (filled gray; nonspecific binding control) and $37^{\circ} \mathrm{C}$ (open black). (F) Superoxide production by hESC-derived (H1-Neu), somatic CD34+ cell-derived (34-Neu), and peripheral blood (PB-Neu) neutrophils in response to PMA. Results are mean \pm SEM of 3 independent experiments performed in triplicate; ${ }^{\star *} P<0.01$. (G) Superoxide production by hESC-derived (H1-EO) and somatic CD34+ cell-derived (34-EO) eosinophils in response to PMA. Results are mean \pm SEM of 3 independent experiments performed in triplicate. (H) Chemotactic activity of hESC-derived, somatic CD34+ cell-derived, and peripheral blood neutrophils. Results are mean \pm SEM of 3 independent experiments performed in triplicate; ${ }^{*} P<0.05$. (I) Chemotactic activity of hESC-derived and somatic CD34+ cell-derived eosinophils. Results are mean \pm SEM of 3 independent experiments performed in triplicate; ${ }^{* \star} P<0.01$. 

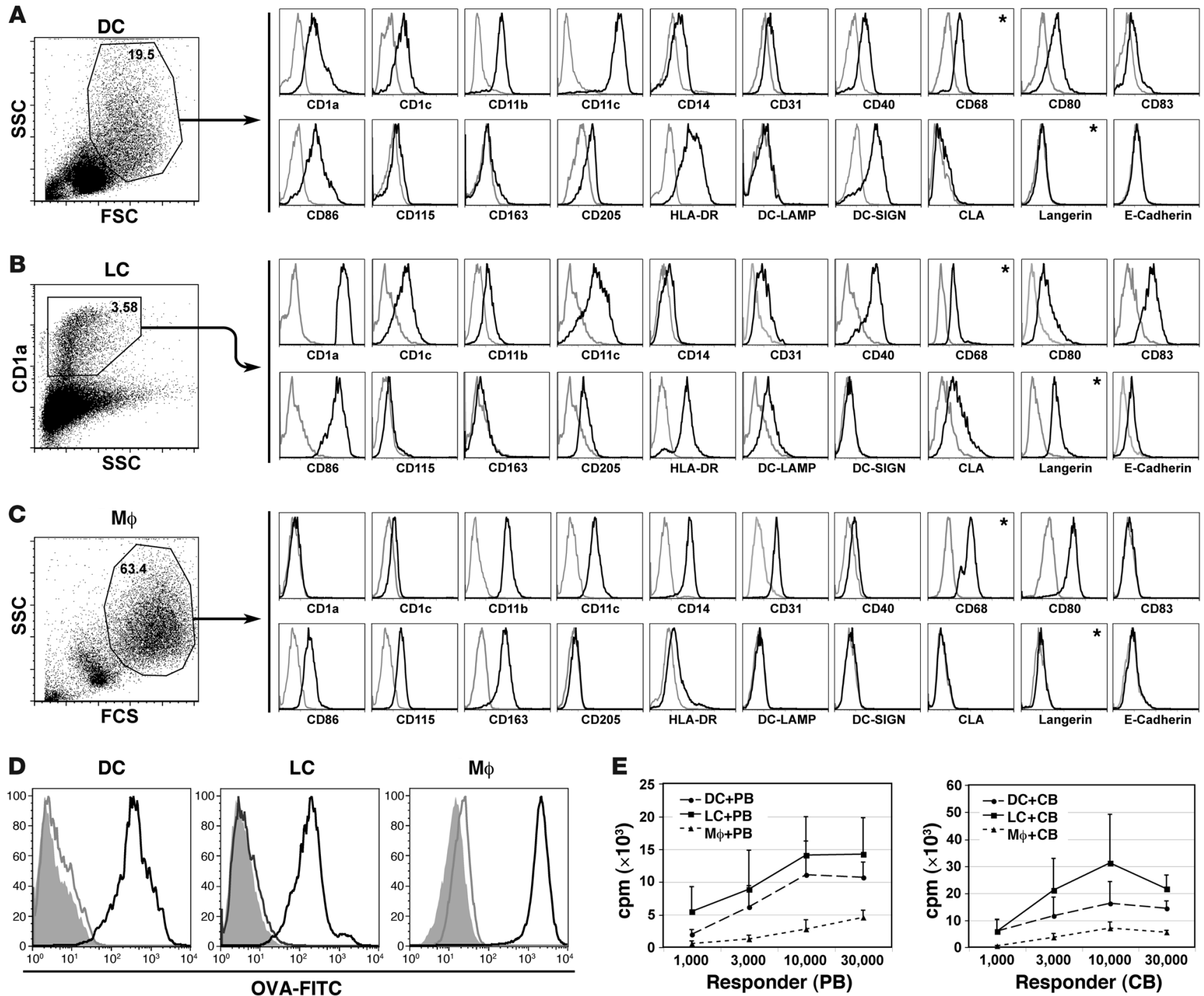

$\mathbf{F}$

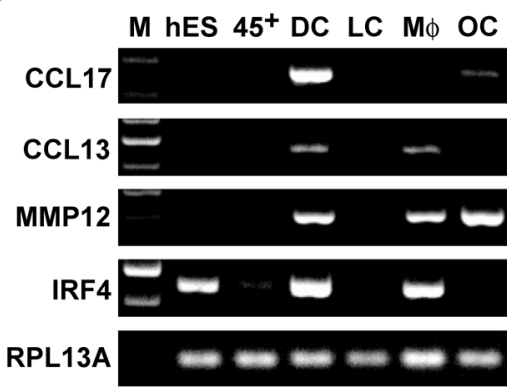

Figure 5

Phenotypic, molecular, and functional analysis of $\mathrm{H} 1 \mathrm{hESC}-$ derived DCs, LCs, and macrophages obtained from isolated CD235a/CD41a-CD45+ cells after 2 days expansion with GM-CSF. FACS analysis of hESC-derived DCs (A), LCs (B), and macrophages (C). Plots show isotype control (gray) and specific antibody (black) histograms; asterisks indicate intracellular staining. Values within dot plots indicate the percentage of cells within the corresponding gate. A representative of 5-10 independent experiments is shown. (D) FACS analysis of OVA uptake and processing by hESC-derived antigen-presenting cells. Plots show isotype control (open gray), cells incubated at $4^{\circ} \mathrm{C}$ (filled gray; nonspecific binding control), and $37^{\circ} \mathrm{C}$ (open black) histograms. (E) Allogeneic stimulatory capacity of hESC-derived antigen-presenting cells. PB, peripheral blood lymphocytes; CB, cord blood lymphocytes. Results are mean \pm SEM of 3 independent experiments performed in triplicate. (F) RT-PCR analysis of gene expression in hESC-derived antigen-presenting cells. M $\phi$, macrophages; OC, osteoclasts. 
A

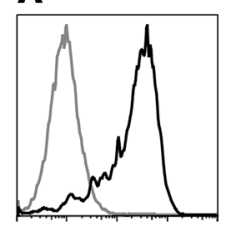

CD11b

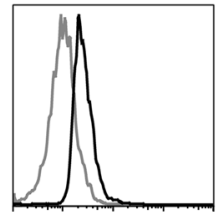

CD51/61

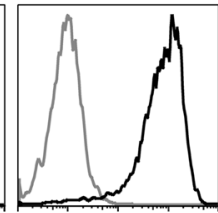

CD11c

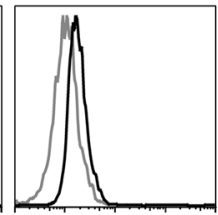

CD115

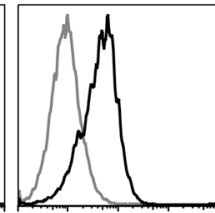

CD14

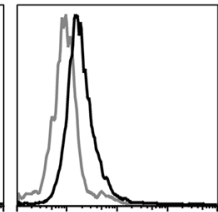

HLA-DR

B

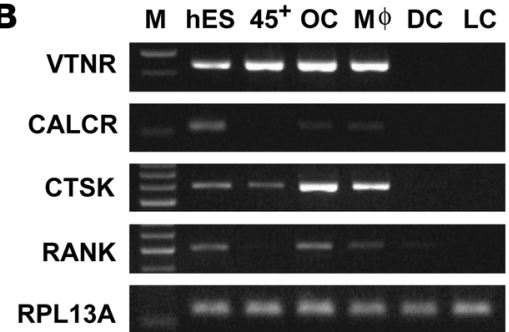

c

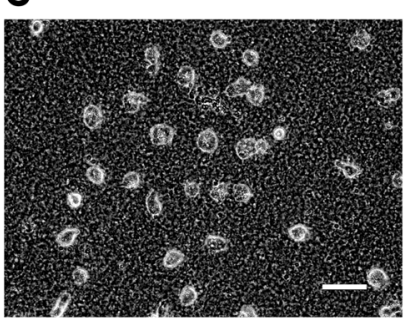

E

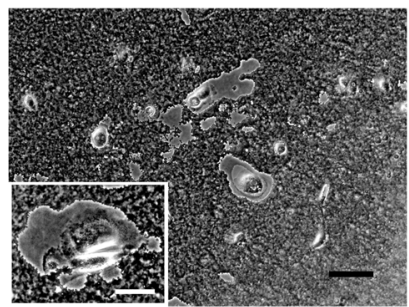

D

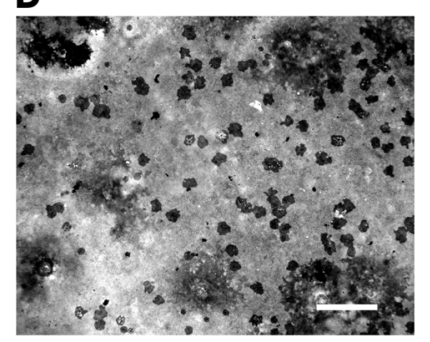

$\mathbf{F}$

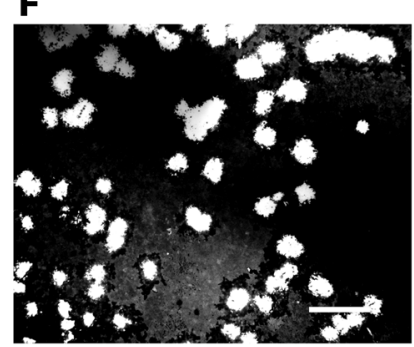

Figure 6

Phenotypic, molecular, and functional analysis of H1 hESC-derived osteoclasts. (A) FACS analysis of hESC-derived osteoclasts. A representative of 3 independent experiments is shown. (B) RT-PCR analysis of gene expression in hESC-derived osteoclasts. Analysis of mineralized matrix-resorptive capacity of hESC-derived macrophages (C and D) and osteoclasts (E and F) using BioCoat osteologic discs. Resorption lacunae around multinucleated cells are clearly visible in osteoclasts cultures (E, inset) but not in cells cultured with M-CSF and IL-1 $\beta$ (C). Visualization of resorption lacunae in macrophage (D) and osteoclast (F) cultures with von Kossa staining. Scale bar: $200 \mu \mathrm{m}(\mathbf{C}-\mathbf{F})$.

tional, and molecular studies. However, the total output of cells of macrophage/dendritic lineage using cells expanded with GMCSF for 2 days was relatively low (Table 1). Since substantial GMCSF-mediated expansion of $\mathrm{CD} 45^{+}$cells was observed by day 8 of differentiation, we assessed the differentiation potential of these cells in an attempt to scale up production. Indeed, on day 8 , GM-CSF cells were capable of differentiation into macrophages and DCs, under conditions similar to that described above, with an apparent increase in yield of these cell types (Table 1). We also noted that maturation of day 8 cells into macrophages occurred much faster and required only 2-3 days of culture with M-CSF and IL-1 $\beta$, instead of the 5-7 days required for cells expanded with GM-CSF for 2 days. In addition, DC and macrophage cultures obtained from day 8 cells contained the highest number of terminally differentiated cells, with only a few immature myeloid cells present. The percentage of CD $1 \mathrm{a}^{+}$cells in $\mathrm{DC}$ cultures from day 8 GM-CSF-expanded cells exceeded $70 \%$, in contrast to only $20 \%$ $\mathrm{CD} 1 \mathrm{a}^{+}$cells seen in cultures from day 2 expanded cells. However, we were unable to generate LCs from myeloid cells expanded with GM-CSF for a period longer than 2 days.

While day 8 GM-CSF expanded CD235a/CD41a-CD45 ${ }^{+}$cells were still capable of differentiation into neutrophils and eosinophils, the cell output was lower as compared with cells obtained after 2 days GM-CSF expansion (Table 1), probably reflecting the relative decrease in granulocytic potential with time. Thus, we concluded that expansion of CD235a/CD $41 \mathrm{a}^{-} \mathrm{CD} 45^{+}$cells with GM-CSF for 2 days provides optimal yield of granulocytes, while expansion of the same cells with GM-CSF for 8 days maximizes yield of DCs and macrophages.
Next, we applied our protocol to generate mature myelomonocytic cells from hiPSCs. In this study, we used 2 hiPSC lines, iPS(foreskin)-1 and iPS(SK46)-M-4-10, which were obtained through reprogramming of neonatal foreskin fibroblasts with POU5F1, SOX2, and NANOG and adult SK46 fibroblasts with POU5F1, SOX2, NANOG, and LIN28 transcription factors $(8,13)$. We were able to obtain neutrophils, eosinophils, macrophages, DCs, LCs, and osteoclasts from both iPS(foreskin)-1 and iPS(SK46)-M-4-10 (Supplemental Figures 3 and 4). The yield of differentiated cells from these hiPSC lines was comparable to that obtained from $\mathrm{H} 1$ hESCs (Supplemental Table 1). These findings support our prior conclusion that the pattern and requirements for hematopoietic differentiation from hiPSCs and hESCs are very similar (13). As we previously noted, both endogenous and retrovirally introduced pluripotency genes were silenced in hiPSC-derived multipotent hematopoietic cells (13), and no reactivation of these genes was observed in terminally differentiated cells (Supplemental Figure 5).

\section{Discussion}

Several studies have reported generation of neutrophils, esosinophils, monocyte/macrophages, DCs, and osteoclasts from mouse ES cells, human bone marrow cells, or mobilized peripheral blood hematopoietic progenitors/stem cells (19-30). Recently, methods for obtaining neutrophils, macrophages, and DCs from hESCs have been described as well (31-35). However, the progenitors giving rise to cells of myeloid lineage are often obscure, especially in differentiation systems employing ES cells. The major advantage and novelty of the differentiation system described in the present 


\section{Table 1}

Yield of H1 hESC-derived CD235/CD41a-CD45+ cells after 2 or 8 days expansion with GM-CSF and mature myeloid cells obtained from expanded cells

\begin{tabular}{lcc} 
Cell type & \multicolumn{2}{c}{ Yield $(\times \mathbf{1 0 6})^{\mathbf{A}}$} \\
& \multicolumn{2}{c}{ GM-CSF expansion } \\
& $\mathbf{2}$ days & $\mathbf{8}$ days \\
CD235a/CD41a-CD45+ cells & $1.3 \pm 0.1$ & $31.7 \pm 4.3$ \\
Neutrophils & $59.3 \pm 4.7$ & $15.9 \pm 1.2$ \\
Eosinophils & $266.9 \pm 34.7$ & $30.8 \pm 11.2$ \\
DCs & $2.2 \pm 0.1$ & $9.5 \pm 0.6$ \\
LCs & $0.5 \pm 0.1$ & $\mathrm{~N} / \mathrm{A}$ \\
Macrophages & $1.1 \pm 0.1$ & $17.9 \pm 3.6$ \\
Osteoclasts & $5.8 \pm 0.3$ & $25.1 \pm 3.0$
\end{tabular}

\begin{abstract}
AYield was calculated as total number of indicated types of cells obtained from one 10-cm dish of hESC/OP9 coculture. To initiate differentiation, $\mathrm{H} 1 \mathrm{hESCs}\left(1.2 \times 10^{6} \pm 0.02 \times 10^{6}\right.$ cells) were collected from one 6-well plate and cocultured with OP9 for 9 days in one 10-cm dish. The $0.18 \times 10^{6} \pm 0.01 \times 10^{6} \mathrm{lin}^{-} \mathrm{CD} 34^{+} \mathrm{CD} 43^{+} \mathrm{CD} 45^{+}$cells were generated at day 9 of differentiation from one $10-\mathrm{cm}$ dish of hESC/OP9 coculture. The absolute numbers of CD235a/CD41a-CD $45^{+}$cells generated after expansion for 2 or 8 days with GM-CSF and differentiated cells generated from these expanded cells are shown. N/A, not applicable (no LCs could be generated from day $8 \mathrm{GM}-\mathrm{CSF}$ expanded cells). Results are mean \pm SEM of $5-10$ experiments.
\end{abstract}

work is that it is based on generation and expansion of prospectively identifiable lin $-\mathrm{CD} 34^{+} \mathrm{CD} 43^{+} \mathrm{CD} 45^{+}$multipotent hematopoietic progenitor from hESCs. This approach facilitates obtaining an essentially homogenous population of mature myeloid cells of a desired type and provides an opportunity to further refine the myeloid lineage fate map, trace myeloid lineage diversification, and create an in vitro model of leukemic transformation in humans using an hESC line engineered to conditionally express oncogenes. In addition, the efficiency of generation of mature myelomonocytic cells by our method was much higher as compared with that achieved with previously described methods. For example Saeki at al. (35) were able to obtain only $10^{6}$ neutrophils per $10^{6} \mathrm{hESCs}$, while our methods made it possible to generate up to $60 \times 10^{6}$ neutrophils or up to $270 \times 10^{6}$ eosinophils per $10^{6}$ hESCs. The major advantage of the Saeki method is that xenogenic feeder cells are not required for differentiation, because it occurs within hESC-derived adherent sac-like structures. However, the Saeki method uses 6 cytokines for neutrophil generation; requires 40 days of culture to obtain a population of cells containing only $50 \%$ neutrophils; and has limited utility, since authors were able to generate neutrophils from only 1 of 3 tested hESC lines. Because hESC-derived lin $-\mathrm{CD} 34^{+} \mathrm{CD} 43^{+} \mathrm{CD} 45^{+}$myeloid progenitors generated from hESCs in OP9 coculture possessed substantial myeloid colony forming and in vitro expansion potential, we found that the most critical limiting factor in scaling up production of mature cells from undifferentiated pluripotent stem cells was the efficiency of generation of these myeloid progenitors from hESCs.

Previously, we reported that hESC-derived myeloid cells expanded with GM-CSF could be used to generate DCs (32). In the present work, we defined the phenotype of hESC-derived myeloid progenitors and demonstrated that inn $^{-} \mathrm{CD} 34^{+} \mathrm{CD} 43^{+} \mathrm{CD} 45^{+}$cells, after expansion with GM-CSF, could generate almost the entire spectrum of myelomonocytic cells, including neutrophils, eosinophils, macrophages, DCs, LCs, and osteoclasts. The protocol for DC differentiation was also optimized by using a higher concentration of GM-CSF $(200 \mathrm{ng} / \mathrm{ml})$ in expansion medium and a lower concentration of TNF- $\alpha(2.5 \mathrm{ng} / \mathrm{ml})$ in the DC differentiation cocktail to improve the yield of functional DCs.

Despite our success in defining conditions for the generation of neutrophils, eosinophils, macrophages, DCs, LCs, and osteoclasts, our multiple attempts to generate basophils from hESC-derived lin' $\mathrm{CD} 34^{+} \mathrm{CD} 43^{+} \mathrm{CD} 45^{+}$cells failed. Although we were able to differentiate peripheral blood $\mathrm{CD} 34^{+}$cells into basophils in the presence of IL-3 and SCF (Supplemental Figure 6), any cytokine combinations known to induce basophil differentiation from somatic $\mathrm{CD} 34^{+}$cells (36) were not sufficient to induce basophilic differentiation from hESC-derived myeloid progenitors. We have not yet determined whether basophil differentiation from hESCs requires a particular, not-yet-identified cytokine cocktail or whether they arise from different multipotent progenitors such as lin- ${ }^{-} \mathrm{CD} 34^{+} \mathrm{CD} 43^{+} \mathrm{CD} 45^{-}$ cells that emerge in hESC/OP9 coculture before $\mathrm{CD} 45^{+}$cells can be detected (12). In addition, we noted that hESC-derived myeloid progenitors are easily skewed to differentiate toward eosinophils. To obtain a pure population of neutrophils, it was essential to limit cytokine combination to G-CSF alone. The addition of other cytokines, such as IL-3, IL-6, or GM-CSF, in an attempt to improve neutrophil yield resulted in production of a mixture of eosinophils and neutrophils, with eosinophils often predominating.

With the exception of neutrophils, which are numerous in peripheral blood and easy to obtain, other types of human myelomonocytic cells are present in tissues in small quantities and are often inaccessible. Eosinophils constitute only $1 \%-3 \%$ of peripheral blood nucleated cells. DCs and osteoclasts are usually obtained from donor-derived $\mathrm{CD}_{3} 4^{+}$hematopoietic progenitors or monocytes, which is a critically limiting factor for generation of sufficient numbers of cells for experimental purposes. The hESCbased approach described here provides a valuable alternative to existing methods for obtaining human myelomonocytic cells. Because hESCs are capable of self-renewal and large-scale expansion, a large number of myeloid precursors and terminally differentiated cells could be generated for not only functional studies, but potentially for therapeutic purposes. hESC-derived myeloid precursors can be also used for myelotoxicity screening of chemotherapeutic drugs, which is currently based on donor-derived bone marrow cells. The major advantage of the use of hESC-derived myeloid progenitors is the possibility for standardization of the myelotoxicity screening assay through elimination of variability related to various donor use.

Reprogramming somatic cells to the pluripotent state provides an unprecedented opportunity to generate immunologically compatible cells for cellular therapies. Recent achievements in the generation of vector- and transgene-free iPSCs brought this possibility closer to reality $(37,38)$. In addition, recent data demonstrating diseases-specific changes in differentiated cells obtained from patientspecific hiPSCs (39) prove the utility of hiPSCs for the study of the mechanisms of diseases. The protocol described here could be used to generate mature myelomonocytic cells from hiPSCs obtained from patients with disorders of host defense in quantities sufficient for functional studies, as well as for drug screening.

\section{Methods}

Cell lines, cytokines, growth factors, and monoclonal antibodies. H1 (NIH code WA01) and H9 (NIH code WA09) hESC lines (WiCell Research Institute) 
were maintained as undifferentiated cells in cocultures containing mouse embryonic fibroblasts (MEFs) (40). iPS(foreskin)-1 hiPSC lines were obtained by reprogramming of newborn foreskin fibroblasts with POU5F1, SOX2, and NANOG (8). The iPS(SK46)-M-4-10 hiPSC line was obtained by reprogramming adult fibroblasts with POU5F1, SOX2, NANOG, and LIN28 (13). Both hiPSC lines were provided by James Thomson (University of Wisconsin-Madison). The hiPSCs were maintained in an undifferentiated state in coculture with MEFs essentially in the same conditions as hESCs (40), but with a higher concentration of bFGF (100 ng/ml; PeproTech) (8). The mouse bone marrow stromal cell line OP9 was obtained from Toru Nakano (Research Institute for Microbial Diseases, Osaka University, Osaka, Japan). This cell line was maintained on gelatinized $10-\mathrm{cm}$ dishes (BD Biosciences) in the OP9 growth medium consisting of $\alpha$-MEM (Invitrogen) supplemented with $20 \%$ defined FBS (HyClone Laboratories). Sterile, recombinant, endotoxin- and pyrogen-free IL-1 $\beta$, IL-3, IL-4, IL-5, M-CSF, TNF- $\alpha$, TGF- $\beta$, and SCF were obtained from PeproTech; G-CSF (Neupogen) from Amgen; GM-CSF (Leukine) from Berlex Laboratories. fMLP, PMA, and vitamin D3 (1 $\alpha, 25$-dihydroxyvitamin D3) were purchased from Sigma-Aldrich. The following monoclonal antibodies were used for flow cytometric analysis: CD10, CD11b, CD13, CD16, CD32, CD64, CD80, CD86, HLA-DR, MPO, lactoferrin (Invitrogen); CD115, CD163, Langerin (R\&D Systems); CD1c, CD15, CD123, CD133, CD203c (Miltenyi Biotec); CD2, CD3, CD7, CD11c, CD14, CD19, CD23, CD24, CD31, CD33, CD34, CD38, CD40, CD41a, CD43 (clone 1G10), CD45, CD51/61, CD56, CD66b, CD90, CD117, DC-SIGN (CD209), CLA, CXCR4, MBP, CD235a (BD Biosciences); CD1a, E-cadherin (CD324), CD68, CD205 (BioLegend); FceRII (eBioscience); DC-LAMP (CD208), CD83 (Immunotech); mouse CD29 (AbD Serotec).

hESC and hiPSC differentiation in OP9 coculture and expansion of myeloid progenitors. Hematopoietic differentiation was induced by transferring the hESCs or hiPSCs onto OP9 feeders as we have previously described in detail $(11,41)$. On day 9 of coculture, differentiated hESCs/hiPSCs were harvested by treatment with collagenase IV (Invitrogen; $1 \mathrm{mg} / \mathrm{ml}$ in $\alpha$-MEM) for 20 minutes at $37^{\circ} \mathrm{C}$, followed by treatment with $0.05 \%$ Trypsin- $0.5 \mathrm{mM}$ EDTA (Invitrogen) for 15 minutes at $37^{\circ} \mathrm{C}$. After trypsin inactivation by FBS, cells were cultured in $\alpha$-MEM containing $10 \%$ FBS and $200 \mathrm{ng} / \mathrm{ml} \mathrm{GM-CSF}$ for $1-8$ days to expand myeloid progenitors in T75 flasks coated with poly 2-hydroxyethyl methacrylate (pHEMA) to create a hydrophobic surface and prevent cell attachment. Subsequently, cells were spun over 20\% Percoll (Sigma-Aldrich) to remove dead cells and cell aggregates as described previously in detail (32, 42). To obtain a CD235a/CD41a-CD45 ${ }^{+}$population of cells enriched in multipotent myeloid progenitors, Percoll-isolated cells were depleted of erythromegakaryocytic progenitors and contaminating OP9 cells by negative MACS selection using CD235a-PE, CD41a-PE, and mouse CD29-PE Abs and antiPE microbeads (Miltenyi Biotec). Subsequently, CD45 cells were isolated from the $\mathrm{CD} 235 \mathrm{a} / \mathrm{CD} 41 \mathrm{a}^{-}$fraction by indirect magnetic-based sorting with anti-human CD45-FITC Abs (BD Biosciences) followed by anti-FITC microbeads (Miltenyi Biotec). Purity of isolated CD235a/CD41a ${ }^{-} \mathrm{CD} 45^{+}$fraction was more than $97 \%$ as verified by FACS analysis.

Directed differentiation of myeloid lineages. A schematic diagram of the differentiation protocol for obtaining progenitors and mature cells of myeloid lineage is presented in Figure 1. GM-CSF-expanded CD235a/CD41a CD $45^{+}$cells were cultured on OP9 cells $\left(2.5 \times 10^{4}\right.$ to $5.0 \times 10^{4}$ cells $/ 3 \mathrm{ml} /$ well of a 6-well plate) in Iscove's modified Dulbecco's medium (IMDM) (Invitrogen) containing 20\% FBS and $100 \mathrm{ng} / \mathrm{ml} \mathrm{G}$-CSF for 8 days to generate neutrophils or $10 \mathrm{ng} / \mathrm{ml} \mathrm{IL-3}$ and $5 \mathrm{ng} / \mathrm{ml} \mathrm{IL}-5$ for $12-14$ days to generate eosinophils. Macrophage, DC, and LC differentiation was performed in low-adherence conditions in pHEMA-coated flasks. For DC and LC differentiation, cells $\left(1 \times 10^{6}\right.$ cells $/ 5 \mathrm{ml} /$ flask $)$ were cultured in Stemline II serum-free hematopoietic stem cell expansion medium (Sigma-Aldrich) supplemented with 1\% EX-CYTE (Millipore) and containing $20 \mathrm{ng} / \mathrm{ml}$ GM-CSF and $20 \mathrm{ng} / \mathrm{ml} \mathrm{IL-4} \mathrm{(DC} \mathrm{cultures)} \mathrm{or} 20 \mathrm{ng} / \mathrm{ml} \mathrm{GM-CSF}$ and 2.5 $\mathrm{ng} / \mathrm{ml}$ TGF- $\beta$ (LC cultures) for 7 days, with $2.5 \mathrm{ng} / \mathrm{ml} \mathrm{TNF-} \alpha$ added to DC cultures or $1 \mathrm{ng} / \mathrm{ml} \mathrm{TNF-} \alpha$ to LC cultures after the first medium change (day 3 of culture). Macrophages were obtained in cultures containing IMDM supplemented with $10 \% \mathrm{FBS}, 20 \mathrm{ng} / \mathrm{ml} \mathrm{M}$-CSF, and $10 \mathrm{ng} / \mathrm{ml} \mathrm{IL-1} \beta$ after 5-7 days of differentiation. Osteoclast differentiation was induced in 2 steps. First, osteoclast progenitors were expanded in $\alpha$-MEM containing $10 \% \mathrm{FBS}, 50 \mathrm{ng} / \mathrm{ml} \mathrm{GM}$-CSF, and $200 \mathrm{nmol}$ vitamin D3 in pHEMA-coated flasks. After 5 days, cells were collected and cultured $\left(5 \times 10^{4}\right.$ cells $/ 3 \mathrm{ml} /$ well) in $\alpha$-MEM containing $10 \% \mathrm{FBS}, 50 \mathrm{ng} / \mathrm{ml} \mathrm{GM}$-CSF, $200 \mathrm{nmol}$ vitamin $\mathrm{D} 3$, and $10 \mathrm{ng} / \mathrm{ml}$ RANKL for an additional 14 days in conventional 6-well plates. For FACS analysis, osteoclasts collected by treatment of cell cultures with PBS-based enzyme-free cell dissociation buffer (Invitrogen).

Isolation of peripheral blood neutrophils and generation of myeloid cells from adult $\mathrm{CD} 34^{+}$progenitor cells. Peripheral blood samples from healthy adult donors were obtained using dextran sedimentation, Ficoll-Paque (Amersham Biosciences; GE Healthcare) centrifugation, and hypotonic lysis of contaminating erythrocytes, as previously described (43). Frozen peripheral blood CD $34^{+}$cells intended for final disposition were obtained from the University of Wisconsin Hematopoietic Stem Cell Laboratory with approval from the University of Wisconsin Institutional Review Board. Donors had previously signed an Institutional Review Board-approved consent. CD34+ cells were cultured on OP9 cells in IMDM (Invitrogen) containing 20\% FBS and $100 \mathrm{ng} / \mathrm{ml} \mathrm{G-CSF}$ and $10 \mathrm{ng} / \mathrm{ml} \mathrm{IL-6}$ to generate neutrophils or 10 $\mathrm{ng} / \mathrm{ml} \mathrm{IL-3}$ and $5 \mathrm{ng} / \mathrm{ml}$ IL-5 to generate eosinophils. To generate DCs, CD $34^{+}$cells were cultured in Stemline II serum-free hematopoietic stem cell expansion medium (Sigma-Aldrich) supplemented with 1\% EX-CYTE (Millipore) and containing $20 \mathrm{ng} / \mathrm{ml} \mathrm{GM-CSF}, 20 \mathrm{ng} / \mathrm{ml} \mathrm{FLT3L,} 20 \mathrm{ng} / \mathrm{ml}$ SCF, $20 \mathrm{ng} / \mathrm{mL}$ IL-4, and $2.5 \mathrm{ng} / \mathrm{ml}$ TNF- $\alpha$ in pHEMA-coated flasks. Similar culture conditions were used to generate LCs, except that the cytokine combination was modified to include $20 \mathrm{ng} / \mathrm{ml} \mathrm{GM}$-CSF, $20 \mathrm{ng} / \mathrm{ml} \mathrm{FLT3L}$, $20 \mathrm{ng} / \mathrm{ml} \mathrm{SCF}, 1 \mathrm{ng} / \mathrm{mL}$ TNF- $\alpha$, and $2.5 \mathrm{ng} / \mathrm{ml} \mathrm{TGF}-\beta$. DCs and LCs were purified from cultures using CD1a-based magnetic sorting as described above. For osteoclast and macrophage differentiation, somatic CD $34^{+}$cells were cultured under the same conditions as the hESC-derived CD235a/ CD41a-CD45 ${ }^{+}$cells described above.

Flow cytometric analysis. Cells were prepared in PBS-FBS (PBS containing $0.05 \%$ sodium azide, $1 \mathrm{mM}$ EDTA, and $2 \% \mathrm{FBS}$ ), supplemented with $2 \%$ normal mouse serum (Sigma-Aldrich), and labeled with a combination of monoclonal antibodies and 7-aminoactinomycin D (7-AAD) for dead cell exclusion. Intracellular staining was performed using FIX \& PERM cell permeabilization reagents (Invitrogen). Samples were analyzed using a FACSCalibur flow cytometer (BD Biosciences) with CellQuest acquisition software (BD Biosciences). List mode files were analyzed by FlowJo software (Tree Star Inc.). Control staining with appropriate isotype-matched control mAbs (BD Biosciences) was included to establish thresholds for positive staining.

Clonogenic progenitor cell assay. Hematopoietic clonogenic assays were performed in 35-mm low-adherent plastic dishes (CELLSTAR; Greiner Bio-One) using $1 \mathrm{ml} /$ dish of MethoCult $\mathrm{GF}^{+} \mathrm{H} 4435$ semisolid medium (StemCell Technologies) as previously described $(11,12,41)$. Colonies were scored after 14-21 days of incubation according to morphological criteria as E-CFC, GEMM-CFC, GM-CFC, G-CFC, and M-CFC.

Functional analysis of mature myeloid cells. Superoxide production by hESCderived neutrophils and eosinophils in response to $10 \mathrm{nM}$ PMA (SigmaAldrich) was evaluated using PeroXOquant Quantitative Peroxide Assay Kit (Pierce, Thermo Scientific). Chemotactic activity was determined by using the modified Boyden method (44). Briefly, neutrophils or eosinophils were put on the PET membrane (3- $\mu \mathrm{m}$ pore size) in an HTS Multiwell Insert System (BD Biosciences) containing $10 \mathrm{nM}$ fMLP (Sigma-Aldrich) in the lower 
chamber, and the number of cells that had moved across the filter membrane was quantified after 3 hours of incubation at $37^{\circ} \mathrm{C}$ and $5 \% \mathrm{CO}_{2}$. FITC-conjugated E. coli and zymosan particles (Molecular Probes, Invitrogen) have been used to assess phagocytosis by FACS. To determine cell autofluorescence and nonspecific binding, we incubated cells with conjugated particles at $4^{\circ} \mathrm{C}$ (negative controls). Ovalbumin uptake and processing were determined using a self-quenched conjugate of ovalbumin (DQ-OVA; Molecular Probes) as we described previously (32). For determination of allogeneic stimulatory capacity, graded quantities $\left(1 \times 10^{3}\right.$ to $3 \times 10^{3}$ cells/well $)$ of macrophages, magnetically purified and irradiated $(35 \mathrm{~Gy}) \mathrm{CD} 1 \mathrm{a}^{+} \mathrm{DCs}$, or LCs were cocultured with $1 \times 10^{5}$ adult peripheral (AllCells) or cord blood (Cambrex) mononuclear cells in RPMI 1640 medium (Invitrogen) containing 5\% human AB serum (Sigma-Aldrich) in 96-well flat-bottom plates. At 6 days of culture, the resulting proliferation of responder cells was evaluated based on incorporation of $\left[{ }^{3} \mathrm{H}\right]$ thymidine (Sigma-Aldrich). To evaluate bone resorption capacity, osteoclasts or terminally differentiated macrophages (negative control) were cultured in $\alpha$-MEM containing $10 \%$ FBS, $50 \mathrm{ng} / \mathrm{ml} \mathrm{GM-CSF}, 200 \mathrm{nmol}$ vitamin D3, and $5 \mathrm{ng} / \mathrm{ml}$ RANKL in BioCoat Osteologic Bone Cell Culture System (BD Biosciences), and calcium resorption was evaluated by von Kossa staining and morphologic analysis of osteologic discs after 7 days of culture according to the manufacturer's instructions.

Cytochemistry. For TRAP staining, osteoclasts were washed with PBS and fixed with $10 \%$ glutaraldehyde for 15 minutes. TRAP was visualized using naphthol AS-MX phosphate (Sigma-Aldrich) as a substrate, with reaction of the product with Fast Violet B salt (Sigma-Aldrich) in TRAP buffer $(0.05 \mathrm{M}$ acetate buffer, $0.03 \mathrm{M}$ sodium tartrate, $0.1 \%$ Triton $\mathrm{X}-100$, $\mathrm{pH}$ 5.0) (45). For EPO staining, cells were fixed in formalin/acetone and stained for 10 minutes in $0.1 \mathrm{M}$ phosphate buffer, $\mathrm{pH}$ 8.0, containing $2 \mathrm{mM}$ 3,3-diaminobenzidine tetrachloride (Sigma-Aldrich), $8 \mathrm{mM} \mathrm{NaCN}$ (Sigma-Aldrich), and $0.009 \% \mathrm{H}_{2} \mathrm{O}_{2}$ (46).
RT-PCR. Total RNA was isolated from cells using TRI Reagent (Ambion) and treated with DNAse (Invitrogen) to remove potentially contaminating DNA. Conventional RT-PCR was performed from $1 \mu \mathrm{g}$ of total RNA using SuperScript III First-Strand synthesis (Invitrogen) and MasterTaq PCR kit (Eppendorf). Real-time quantitative PCR (Q-PCR) was performed using the $\mathrm{RT}^{2}$ SYBR Green/ROX qPCR Master Mix (SABiosciences) on an ABI Prism 7700 Sequence Detection System (Applied Biosystem). The PCR primers used are listed in Supplemental Table 2. The expression level of selected genes was calculated relative to RPL13A as a reference gene using the following formula: relative expression $=2^{\text {(Ct ref-Ct gene) }}(47)$.

Statistics. The significance of differences between the mean values of the tested samples was determined by 2-tailed Student's $t$ test for unpaired values. $P$ values less than 0.05 were considered significant.

\section{Acknowledgments}

We thank James Thomson for providing hiPSC cell lines, Toru Nakano for providing OP9 cells, Alexey Pereverzev for the helpful discussion on evaluation of osteoclast function, and Joan Larson for editorial assistance. This work is supported by NIH grants HL085223 (to I.I. Slukvin) and NIH grant P51 RR000167 to the National Primate Research Center, University of Wisconsin-Madison.

Received for publication January 15, 2009, and accepted in revised form June 10, 2009.

Address correspondence to: Igor I. Slukvin, Department of Pathology and Laboratory Medicine, Wisconsin National Primate Research Center, University of Wisconsin, 1220 Capitol Court, Madison, Wisconsin 53715, USA. Phone: (608) 263-0058; Fax: (608) 265-8984; E-mail: islukvin@wisc.edu.
1. Rosmarin, A.G., Yang, Z., and Resendes, K.K. 2005. Transcriptional regulation in myelopoiesis: hematopoietic fate choice, myeloid differentiation, and leukemogenesis. Exp. Hematol. 33:131-143.

2. Rosenbauer, F., and Tenen, D.G. 2007. Transcription factors in myeloid development: balancing differentiation with transformation. Nat. Rev. Immu nol. 7:105-117.

3. Rado, T.A., Wei, X.P., and Benz, E.J., Jr. 1987. Isolation of lactoferrin cDNA from a human myeloid library and expression of mRNA during normal and leukemic myelopoiesis. Blood. 70:989-993.

4. Khanna-Gupta, A., Kolibaba, K., Zibello, T.A., and Berliner, N. 1994. NB4 cells show bilineage potential and an aberrant pattern of neutrophil secondary granule protein gene expression. Blood. 84:294-302.

5. Baumann, M.A., and Paul, C.C. 1998. The AML14 and AML14.3D10 cell lines: a long-overdue model for the study of eosinophils and more. Stem Cells. 16:16-24.

6. Fischkoff, S.A. 1988. Graded increase in probability of eosinophilic differentiation of HL-60 promyelocytic leukemia cells induced by culture under alkaline conditions. Leuk. Res. 12:679-686.

7. Thomson, J.A., et al. 1998. Embryonic stem cell lines derived from human blastocysts. Science. 282:1145-1147.

8. Yu, J., et al. 2007. Induced pluripotent stem cell lines derived from human somatic cells. Science. 318:1917-1920.

9. Takahashi, K., et al. 2007. Induction of pluripotent stem cells from adult human fibroblasts by defined factors. Cell. 131:861-872.

10. Park, I.H., et al. 2008. Reprogramming of human somatic cells to pluripotency with defined factors. Nature. 451:141-146.

11. Vodyanik, M.A., Bork, J.A., Thomson, J.A., and
Slukvin, I.I. 2005. Human embryonic stem cellderived CD34+ cells: efficient production in the coculture with OP9 stromal cells and analysis of lymphohematopoietic potential. Blood. 105:617-626.

12. Vodyanik, M.A., Thomson, J.A., and Slukvin, I.I. 2006. Leukosialin (CD43) defines hematopoietic progenitors in human embryonic stem cell differentiation cultures. Blood. 108:2095-2105.

13. Choi, K., et al. 2009. Hematopoietic and endothelial differentiation of human induced pluripotent stem cells. Stem Cells. 27:559-567.

14. Antal-Szalmas, P., et al. 1997. Quantitation of surface $\mathrm{CD} 14$ on human monocytes and neutrophils. J. Leukoc. Biol. 61:721-728.

15. Wright, S.D., et al. 1991. Activation of the adhesive capacity of CR3 on neutrophils by endotoxin: dependence on lipopolysaccharide binding protein and CD14. J. Exp. Med. 173:1281-1286.

16. Tachimoto, H., and Bochner, B.S. 2000. The surface phenotype of human eosinophils. Chem. Immunol. 76:45-62.

17. Santegoets, S.J., et al. 2008. Transcriptional profiling of human skin-resident Langerhans cells and CD1a+ dermal dendritic cells: differential activation states suggest distinct functions. J. Leukoc. Biol. 84:143-151.

18. Valladeau, J., and Saeland, S. 2005. Cutaneous dendritic cells. Semin. Immunol. 17:273-283.

19. Lieber, J.G., et al. 2004. The in vitro production and characterization of neutrophils from embryonic stem cells. Blood. 103:852-859.

20. Hamaguchi-Tsuru, E., et al. 2004. Development and functional analysis of eosinophils from murine embryonic stem cells. Br. J. Haematol. 124:819-827.

21. Fairchild, P.J., et al. 2000. Directed differentiation of dendritic cells from mouse embryonic stem cells. Curr. Biol. 10:1515-1518.

22. Senju, S., et al. 2003. Generation and genetic modi- fication of dendritic cells derived from mouse embryonic stem cells. Blood. 101:3501-3508.

23. Yamane, T., et al. 1997. Development of osteoclasts from embryonic stem cells through a pathway that is c-fms but not c-kit dependent. Blood. 90:3516-3523

24. Hino, M., et al. 2000. Ex vivo expansion of mature human neutrophils with normal functions from purified peripheral blood CD34+ haematopoietic progenitor cells. Br. J. Haematol. 109:314-321.

25. Haylock, D.N., To, L.B., Dowse, T.L., Juttner, C.A., and Simmons, P.J. 1992. Ex vivo expansion and maturation of peripheral blood CD34+ cells into the myeloid lineage. Blood. 80:1405-1412.

26. Smith, S.L., et al. 1993. Expansion of neutrophil precursors and progenitors in suspension cultures of CD34+ cells enriched from human bone marrow. Exp. Hematol. 21:870-877.

27. Rosenberg, H.F., Dyer, K.D., and Li., F. 1996. Characterization of eosinophils generated in vitro from CD34+ peripheral blood progenitor cells. Exp. Hematol. 24:888-893.

28. Thavarajah, M., Evans, D.B., and Kanis, J.A. 1991. $1,25(\mathrm{OH}) 2 \mathrm{D} 3$ induces differentiation of osteoclastlike cells from human bone marrow cultures. Biochem. Biophys. Res. Commun. 176:1189-1195.

29. MacDonald, B.R., et al. 1987. Formation of multinucleated cells that respond to osteotropic hormones in long term human bone marrow cultures. Endocrinology. 120:2326-2333.

30. Caux, C., et al. 1996. CD34+ hematopoietic progenitors from human cord blood differentiate along two independent dendritic cell pathways in response to GM-CSF+TNF alpha. J. Exp. Med. 184:695-706.

31. Karlsson, K.R., et al. 2008. Homogeneous monocytes and macrophages from human embryonic stem cells following coculture-free differentiation in 
M-CSF and IL-3. Exp. Hematol. 36:1167-1175.

32. Slukvin, I.I., Vodyanik, M.A., Thomson, J.A., Gumenyuk, M.E., and Choi, K.D. 2006. Directed differentiation of human embryonic stem cells into functional dendritic cells through the myeloid pathway. J. Immunol. 176:2924-2932.

33. Su, Z., Frye, C., Bae, K.M., Kelley, V., and Vieweg, J. 2008. Differentiation of human embryonic stem cells into immunostimulatory dendritic cells under feeder-free culture conditions. Clin. Cancer Res. 14:6207-6217.

34. Senju, S., et al. 2007. Genetically manipulated human embryonic stem cell-derived dendritic cells with immune regulatory function. Stem Cells. 25:2720-2729.

35. Saeki, K., et al. 2008. A feeder-free and efficient production of functional neutrophils from human embryonic stem cells. Stem Cells. 27:59-67.

36. Arock, M., Schneider, E., Boissan, M., Tricottet, V., and Dy, M. 2002. Differentiation of human baso- phils: an overview of recent advances and pending questions. J. Leukoc. Biol. 71:557-564.

37. Yu, J., et al. 2009. Human induced pluripotent stem cells free of vector and transgene sequences. Science. 324:797-801.

38. Zhou, H., et al. 2009. Generation of induced pluripotent stem cells using recombinant proteins. Cell Stem Cell. 4:381-384.

39. Ebert, A.D., et al. 2009. Induced pluripotent stem cells from a spinal muscular atrophy patient. Nature. 457:277-280.

40. Amit, M., et al. 2000. Clonally derived human embryonic stem cell lines maintain pluripotency and proliferative potential for prolonged periods of culture. Dev. Biol. 227:271-278.

41. Vodyanik, M.A., and Slukvin, I.I. 2007. Hematoendothelial differentiation of human embryonic stem cells. Curr. Protoc. Cell Biol. Chapter 23, unit 23.6.

42. Vodyanik, M.A., and Slukvin, I.I. 2007. Directed differentiation of human embryonic stem cells to dendritic cells. Methods Mol. Biol. 407:275-293.

43. Heit, B., Tavener, S., Raharjo, E., and Kubes, P. 2002. An intracellular signaling hierarchy determines direction of migration in opposing chemotactic gradients. J. Cell Biol. 159:91-102.

44. Boyden, S. 1962. The chemotactic effect of mixtures of antibody and antigen on polymorphonuclear leucocytes. J. Exp. Med. 115:453-466.

45. Minkin, C. 1982. Bone acid phosphatase: tartrateresistant acid phosphatase as a marker of osteoclast function. Calcif. Tissue Int. 34:285-290.

46. Ten, R.M., Pease, L.R., McKean, D.J., Bell, M.P., and Gleich, G.J. 1989. Molecular cloning of the human eosinophil peroxidase. Evidence for the existence of a peroxidase multigene family. J. Exp. Med. 169:1757-1769.

47. Muller, P.Y., Janovjak, H., Miserez, A.R., and Dobbie, Z. 2002. Processing of gene expression data generated by quantitative real-time RT-PCR. Biotechniques. 32:1372-1374, 1376, 1378-1379. 